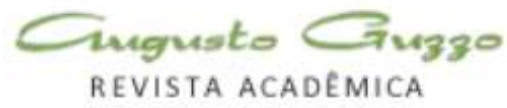

\title{
A Otimização De Robôs De Pintura Na Indústria Automotiva
}

\section{Paint Robots Optimization In Automotive Industry}

\author{
Roberto Angelo Martello¹, Claudemir Claudino Alves², Luciano Galdino³
}

\begin{abstract}
1.Roberto Angelo Martello: Technical Services Representative - Axalta Coating Systems. Graduando em Tecnologia da Mecatrônica na Faculdade ENIAC. E-mail: roberto_martello@hotmail.com.br.

2.Claudemir Claudino Alves: Professor de Engenharia Mecânica, Automação e Manutenção - Faculdade ENIAC. Mestre em Engenharia Mecânica pela UNITAU. E-mail: claudemirclaudino@gmail.com.

3.Luciano Galdino: Professor de Física e Elementos de Máquina na Faculdade ENIAC. Mestre em Ciências Exatas e da Terra na área de Física Nuclear pela USP, especializado em Física pela USP e Licenciado em Matemática pela UNG. E-mail: lucianogaldino1@yahoo.com.br.
\end{abstract}

\section{Resumo}

Nos dias atuais, não só a instalação de robôs nos pátios fabris tem demandado vantagens para empresas que investe nessa tecnologia, o principal desafio é tirar o "máximo" de aproveitamento do Lead Time que essas máquinas possuem, pois quanto maior a eficiência em sua utilização, mais rápido e seguro será o retorno do investimento destinado a um projeto de automação de manufatura. Este Artigo visa exatamente mostrar como se podem utilizar ferramentas administrativas para controle de eficiência, OEE (Overall Equipment Effectiveness) ou Eficácia Geral de Equipamentos combiná-las aos conhecimentos técnicos e teóricos de seus sistemas de aplicação (Carga Direta e Indireta/ Corona), e ao conhecimento do comportamento físico da cobertura submetida a altas tensões de aplicação de tintas e combiná-las para que um robô de pintura possa ter um melhor aproveitamento. Instalar um robô em uma unidade fabril possui como vantagem aumentar a qualidade e a produção, reduzindo o custo do produto final, já a desvantagem é o preço a pagar por essas facilidades.

Palavras-chave: Pintura, robô, OEE.

\begin{abstract}
In the actual days, having an installed robot in a factory leads advantages for a company that makes investments in this technology. The main challenge is, make maximum uses of these machines' Lead-Time, most higher is the effectiveness on an equipment's correct uses, faster and safer payback is achieved. This Article aims exactly on how to use administrative tools for effectiveness control, OEE (Overall Equipment Effectiveness), combine them with theory and technical knowledge on paint application systems (Direct and Indirect Charge/ Corona), knowledge on coatings' physical behavior interacting with high application tensions and combine them to make better uses of a robot that was not being effectively used as we'll foresee. Installing
\end{abstract}


a robot in a manufacturing unit has the advantage of increasing the quality and production, reducing the cost of the final product, since the downside is the price to pay for these facilities.

Keywords: Paint Application, robot, OEE. 


\section{Introdução}

É importante salientar que o conhecimento técnico em robôs de aplicação e a tecnologia de aplicação da tinta são muito importantes para melhor sustentar o processo de otimização. Como estamos lidando com grandezas elétricas juntamente com produtos inflamáveis, um profundo conhecimento técnico da norma NFPA 33, (National Fire Protection Association) que regem robôs de aplicação em cabines de pintura se faz necessário, além de que o ambiente de trabalho para pessoas que realizam esse processo é cheio de perigos à saúde, os quais incluem gases nocivos e prejudiciais no ar, risco de fogo repentino (flash fires) e ruído do bico da pistola pulverizadora (GROOVER, 2011), bem como, no sistema de aplicação Waterborne onde, apenas o spray de tinta é polarizado com alta tensão, fazendo com que a bomba de tinta, tubulações e reservatórios não recebam potencial elétrico, o que ocorre de forma oposta ao sistema Solvetborne, no caso apresentado. A construção física do robô, salas de tinta e sistema de bombeamento devem ser consideradas na análise, pois se deve isolar um sistema de aplicação da tecnologia Waterborne no mínimo $400 \mathrm{~mm}$ de um ponto de aterramento, sua nova instalação contempla essa exigência bem como, exigências necessárias para aplicação de produtos em Solventborne.
O equipamento em questão estava sendo utilizado para aplicações de tinta Waterborne em uma cabine de aplicação preparada para essa tecnologia, através da aplicação por carga indireta, restringindo-o apenas 30\% dos fluxos de aplicação de tinta da empresa, além desse não estar com toda sua capacidade produtiva à disposição.

Somado ao conhecimento de toda tecnologia empregada no funcionamento dos robôs, materiais a serem aplicados e normas de segurança, foi ainda necessário um aprofundamento teórico de uma ferramenta administrativa para que o equipamento fosse disponibilizado para aplicações no setor de pesquisa e desenvolvimento $(\mathrm{R} \& \mathrm{D})$, realizado uma análise de sua eficiência média e utilizado o sistema OEE (Overall Equipment Effectiveness) da Toyota. Esse sistema é uma ferramenta do TPM (Total Maintenance Management) que visa a medição da eficiência média do equipamento através dos indicadores de disponibilidade, performance e qualidade, obtidos com o acompanhamento de todas etapas produtivas de equipamentos e ou processos.

Tendo a definição clara de que esse equipamento possui definidamente um Sistema de Controle - Sistema que executa a operação física e um Equipamento de Controle - Equipamento que recebe informações provenientes do operador, do 
processo a ser controlado etc. (GEORGINI, 2013) e mesmo assim não sendo um robô de pintura automotiva com 6 ou 7 eixos, o equipamento em questão, realiza funções de aplicações necessárias para laboratórios, reproduzindo com fidelidade resultados obtidos em pinturas de carrocerias nas montadoras, porém, sendo aplicadas em chapas que são medidas e usadas de referência comparativa com padrões globais de pintura de cada montadora. Um robô de coordenadas cartesianas, ou robô cartesiano, pode se movimentar em linha reta, em deslocamentos horizontais e verticais. As coordenadas cartesianas especificam um ponto do espaço em função de suas coordenadas $x, y$ e $z$. Esses robôs têm três articulações deslizantes e são codificados como PPP (ROSÁRIO, 2005).

\section{A Alta Tensão Em Aplicações De Tinta}

O princípio de funcionamento de um transformador de tensão é relativamente simples, ao aplicar no primário uma tensão variável no tempo, ele produz também uma corrente variável e um fluxo magnético variável. Esse fluxo induz uma tensão no secundário, cuja amplitude pode ser maior, menor ou igual a amplitude do primário, dependendo unicamente da relação de espiras (para o caso do transformador ideal) (CRUZ \& CHOUERI, 2013).
No caso de aplicações em tintas não é diferente, a geração de alta tensão usa um dispositivo chamado "Gerador de Cascata" ilustrado na Figura 1, (tendo seu funcionamento parecido com o flyback de televisores a tubo) o qual recebe na entrada uma tensão de 0 a $36 \mathrm{~V}$ e pode gerar até $100 \mathrm{kV}$ com $500 \mu \mathrm{A}$ em sua saída, porém, há necessidade de um controlador para alta tensão como exemplificado na Figura 2, esse realiza a medição dinâmica no processo e altera os níveis de tensão na entrada do Gerador de Cascata para que o nível de tensão ou corrente seja atingido.

Figura 1 - Gerador Cascata

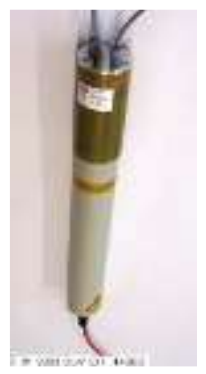

Fonte: Manual do Fabricante Dürr, 2004

Figura 2 - Controlador de Alta Tensão

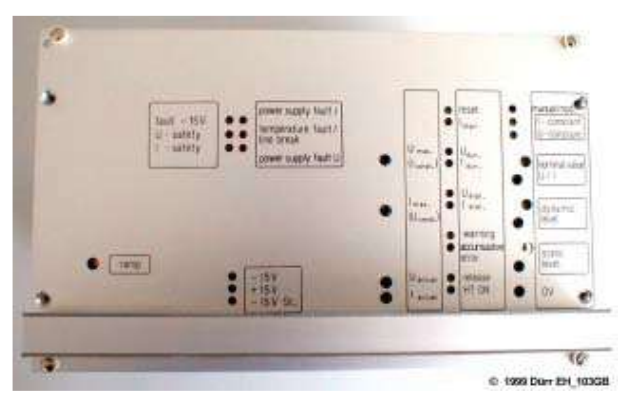

Fonte: Manual do Fabricante Dürr, 2004

Tintas à base de água têm níveis muito baixos de solventes voláteis indesejáveis a ambiente hostis, mas como a tinta é condutora, 
apresenta alguns desafios adicionais em isolar a tinta a ser pulverizadas do resto do sistema de recirculação de tinta (COLESTOCK, 2013).

Com base nessas afirmações, em aplicações da tecnologia em água, a tinta é polarizada com alta tensão de 70 a $80 \mathrm{kV}$, porém, pelo material aplicado ser à base de água, esse é muito condutivo e sensível à eletricidade, a tinta é polarizada por meio de campo magnético (Carga Indireta/ Corona), onde o controle da aplicação é dado em micro Ampére $(\mu \mathrm{A})$, controle necessário para que o dielétrico entre o spray de tinta e o material a ser pintado não seja rompido, o qual ocorreria faísca e fuga de alta tensão, podendo causar danos irreversíveis nos piores casos, mas também a má uniformidade da condução que implicaria na má orientação das partículas de tinta essenciais para formação de cor e aderência.

Através da figura 3, pode-se analisar as linhas de campo interagindo com o spray de tinta.
Figura 3 - Carga Indireta/Corona e Carga

Direta

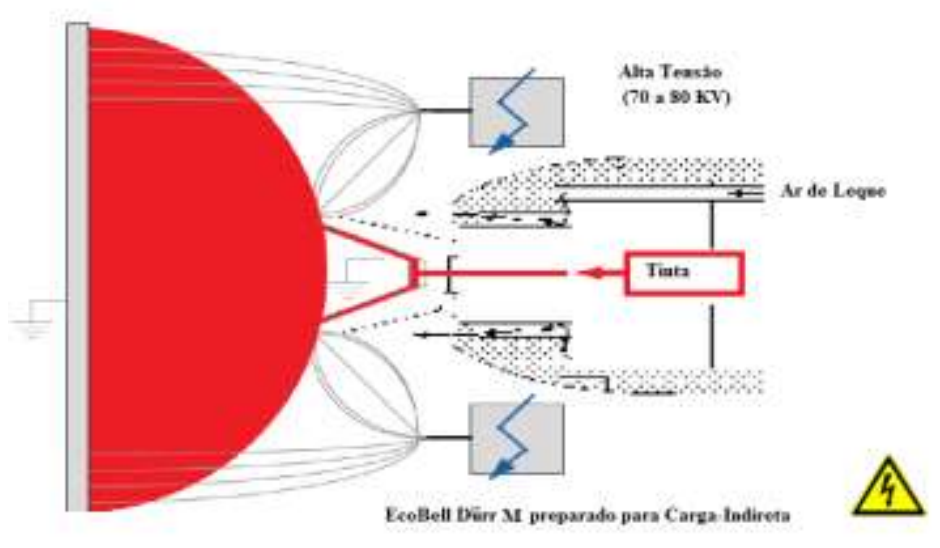

Fonte: High Voltage System Presentation LIMAN, tradução feita pelos autores, 2014.

Já em aplicações da tecnologia em solvente, os produtos são polarizados com tensões entre 80 e $90 \mathrm{kV}$ e por se tratarem de materiais com resistência mais elevada que a anteriormente citada, a tinta é polarizada desde seu reservatório até o spray de tinta (Carga Direta), conforme indicado pela figura 4. Para o controle de cargas diretas é utilizada a tensão que garante uniformidade na aplicação e aspectos de cor e aderência, mesmo assim, devem-se respeitar os níveis de tensão de aplicação e distância entre o aplicador de tinta e o corpo de prova a ser pintado, para não haver o rompimento do dielétrico, causando faíscas. 
Figura 4 - Carga Indireta/Corona e Carga

Direta

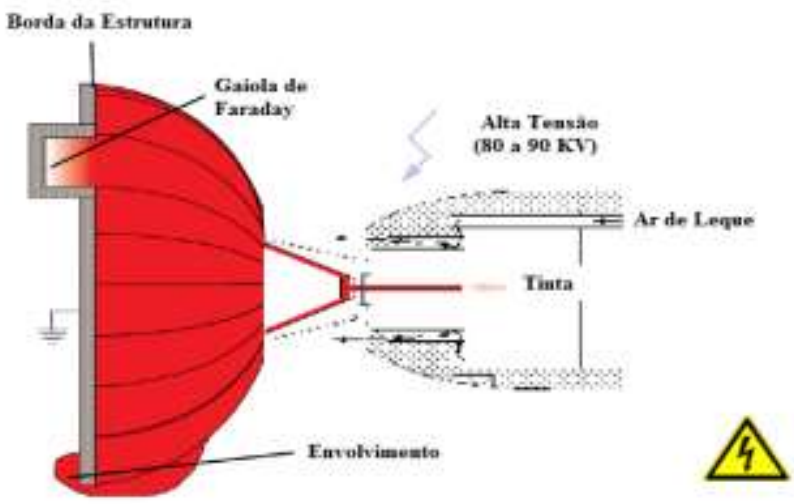

Fonte: High Voltage System Presentation LIMAN, tradução feita pelos autores 2014.

Um fator que contribui para que a operação venha a conhecer sobre $\mathrm{O}$ funcionamento detalhado do equipamento, bem como a manutenção tem como base fundamental conhecer sua operação, além de ser uma ajuda mutua para sanar eventuais problemas decorrentes das atividades exercidas. A prática ensina que os conhecimentos de hidráulica, pneumática, eletricidade, eletrônica e suas combinações são igualmente importantes e necessários em automação. Portanto, não devemos valorizar um conhecimento em relação ao outro, mas sim procurar enquadrá-los nas suas aplicações específicas, levando sempre em consideração os factores técnicos, sociais e principalmente econômicos (BONACORSO, 2013).

\section{Toyota Oee - Overall Equipment} Effectiviness.

Criado pela Toyota para ser um sistema de autogerenciamento, o TPM (Total Productive Maintenance) possui várias ferramentas para gerenciamento de processos, setores e equipamentos, Taiichi Ohno e Eiji Toyoda desenvolvedores desse sistema, que posteriormente ficaria conhecido como Lean Manufacturing, elaboraram essas ferramentas de controle que visam a diminuição de desperdícios, quebras e por sua vez, agregam valor no produto final, bem como, qualidade.

Uma dessas ferramentas é o OEE (Overall Equipment Effectiveness), além de todo controle dos recursos utilizados para a realização de alguma atividade, o OEE viabiliza a padronização das operações de todas as etapas de todos processos envolvidos, possibilitando que cada etapa seja tratada individualmente, tirando todo proveito dessa (SANTOS \& SANTOS, 2010).

Para que as metas estabelecidas pela OEE sejam atingidas, uma mudança cultural é necessária, onde basicamente a aproximação do setor de operações e manutenção seja aumentada, levando treinamento e compromisso a todos envolvidos com o processo, aumentando a intimidade e ideias de melhoria e rotinas de inspeção (NAKAJIMA, 1989). OEE é mensurado 
a partir da estratificação das seis grandes perdas e calculado através do produto dos índices disponibilidade, performance e qualidade, obtidos da seguinte forma:

\section{Índice de Disponibilidade:}

A Disponibilidade pode se definir como sendo o tempo em que o equipamento, sistema ou instalação está disponível para operar em condições de produzir. Seu cálculo pode ser definido como a relação entre o tempo em que o maquinário ficou disponível para trabalho em relação ao tempo total (KARDEC; NASCIF, 2002). É representada pela equação 1:

Índice de Disponibilidade $=(\underline{\mathrm{TD}-\mathrm{PNP}}) \times 100$ (1)

$$
\text { (TD- PP) }
$$

$\mathrm{TD}=$ Tempo disponível.

$\mathrm{PNP}=$ Parada não programada.

$\mathrm{PP}=$ Parada programada.

Desempenho (ou Performance): É o quanto o equipamento trabalha próximo do tempo de ciclo ideal para produzir uma peça (BARIANI, 2006). Essa deve ser descrita conforme a equação 2 :

Índice de Performance $=\underline{\text { PBP }} \times 100$ (2)
DI

$\mathrm{PBP}=$ Assertividade dos produtos.

$\mathrm{DI}=$ Disponibilidade.

Qualidade: É o número total de peças boas produzidas comparadas com o número total de peças produzidas (BARIANI, 2006), e deve ser representada conforme equação 3 :

Índice de Qualidade $=\underline{\text { PBP }} \times 100$ (3)

TPP

$\mathrm{PBP}=$ Peças boas produzidas.

$\mathrm{TPP}=$ Total de peças produzidas.

A multiplicação dos Índices de Disponibilidade x Índice de Performance x Índice de Qualidade resulta no OEE, (NAKAJIMA, 1986), um OEE de $85 \%$ deve ser buscado como meta ideal para os equipamentos. Empresas que obtiveram OEE superior a 85\% ganharam prêmio TPM Award.

Quando um ou mais desses índices estiverem abaixo dessa margem, existe a oportunidade de melhora. A OEE permite indicar áreas onde devem ser desenvolvidas melhorias bem como pode ser utilizado como benchmark, permitindo quantificar as melhorias desenvolvidas nos equipamentos, células ou linhas de produção ao longo do tempo (SANTOS \& SANTOS, 2010), 
os itens mais conhecidos como fatores agravantes para diminuição desses índices são:

Falhas dos Equipamentos: Inesperadas ocorrências como falta de matéria prima, falta de mão de obra ou quebra. Essas falhas ajudam a reduzir o tempo disponível do equipamento.

Setup e Ajustes: Necessários para o início e também para correção de problemas durante a produção. Reduzir essas ocorrências e/ou tempo de atuação delas aumentará o tempo disponível.

Troca de ferramentas: Assim como citado no item anterior, é necessário e deve ser estudado ao máximo todas as suas etapas. Muitas vezes deve se utilizar o tempo de outras paradas para execução desse, utilizar dispositivos para facilitar o trabalho, e outros.

Acionamento: Conhecido como tempo de Warm up, é o tempo que o equipamento ou processo leva para atingir sua plena atividade com possível redução de tempo, porém, devem-se respeitar as limitações e especificações do equipamento.

Pequenas paradas ou pequenos períodos de ociosidade: A soma de pequenas paradas podem resultar em uma catastrófica perda de tempo ao final do processo, sem contar energia para ocorrer todo o $W$ arm up citado anteriormente.
Velocidade: ao se projetar uma máquina, algumas variáveis podem ser esquecidas, além de desgastes ocorrentes do tempo de uso, assim, o equipamento possuirá um regime de trabalho inferior ao esperado. Defeitos e retrabalhos: Um equipamento que produz muitas peças defeituosas além de eventuais perdas de material também ocasiona tempo para retrabalho, consumindo tempo hábil para fabricação.

Desligamento: Algumas manutenções exigem o desligamento total do equipamento, o desligamento parcial, o qual deve ser anteriormente definido entre o fabricante e a manutenção, é uma solução inteligente para redução de perda de tempo, não necessidade que toda uma linha seja desligada, nessa linha pode haver túneis e estufas que possuem um elevado tempo de $W$ arm up, resfriar uma estufa que estava a $200^{\circ} \mathrm{C}$ para uma manutenção rápida em uma esteira, e em seguida reaquecer essa estufa, além de levar tempo para uma total estabilização, ainda consome muito mais energia do que mantê-la ligada durante uma manutenção.

\section{Plano De Melhoria}

O controle dinâmico tem por objetivo estabelecer o comportamento estático e dinâmico dos sistemas físicos, tornando-os mais obediente aos operadores e mais imune às perturbações dentro de certos limites. Utiliza sempre medidas 
de variáveis internas e/ou de saída do sistema, num esquema de realimentação ou feedback em torno do sistema original. Este é um conceito de incalculável poder tecnológico para o aperfeiçoamento de inúmeros processos, seja em velocidade e precisão, seja em custo (MORAES, 2007), Para haver um aumento no desenvolvimento de novos produtos e diminuição do tempo para eventuais soluções junto aos clientes, o setor R\&D (Research and Development) necessita conciliar o uso de robôs de aplicação de tintas automotivas e cabines de aplicação juntamente com o setor QC (Quality Control). Dispondo apenas de 2 horas diárias para aplicações em Solventborne (Robô 2) e também 2 horas diárias para aplicações $W$ aterborne (Robô 1), o setor R\&D possuía o Índice OEE conforme demonstrado no quadro 1. 
Quadro 1 - OEE antes da melhoria

OEE - Overall Equipment Effectiveness

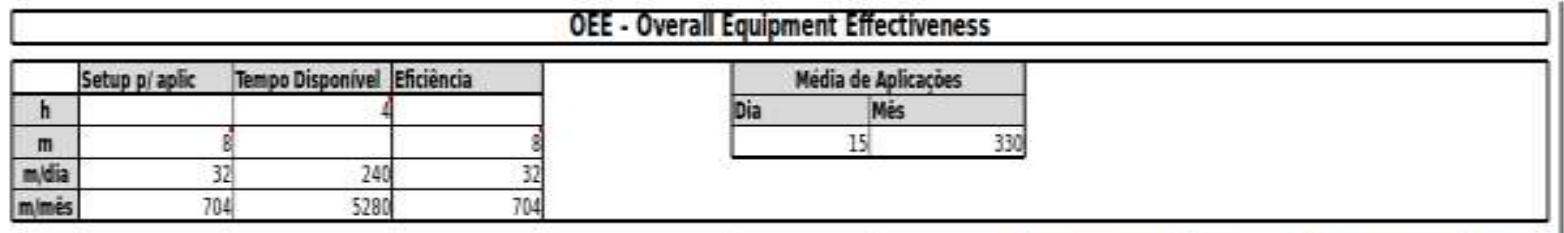

\begin{tabular}{|c|c|c|c|c|c|c|c|c|c|c|}
\hline Més & P.Nèo Prog, (min] & P.Prog.(min) & Temp Disp, (min) D & Disp de Aplicacio (pc)] & Trabalhos (pc) if & Reprodutives (pc) 1 & 1 Dispocibridade & L. Performance & 1. Prod. Aprovados & O.E.E \\
\hline an & 600 & d & 4808 & 300 & 285 & 245 & 0,875 & 0,81666666667 & 0.8596491226 & $61,43 \%$ \\
\hline Fev & 720 & 240 & 4560 & 225 & 273 & 235 & 0,8421052632 & 0,8245614035 & 0.8606058608 & $59,77 \%$ \\
\hline Mar & 1200 & 360 & 3960 & 248 & 230 & 190 & 0,696969697 & 0,7676767677 & 0.8260869565 & $44,20 \%$ \\
\hline $\mathrm{Abr}$ & 480 & 180 & 4860 & 304 & 297 & 252 & 0,9012345679 & 0,8296296296 & 0.8484848485 & $63,44 \%$ \\
\hline Mail & 600 & 240 & 4566 & 285 & 283 & 244 & 0,8694210526 & $0,856142350 / 9$ & 0.8621908127 & $64,10 \%$ \\
\hline un & 480 & 180 & 4860 & 304 & 297] & 254 & 0,9012345679 & 0,8362139918 & 0.8552188558 & $64,45 \%$ \\
\hline ul & 360 & 300 & 4988 & 311 & 308 & 267 & 0,9277102434 & 0,8578313253 & 0.8668831169 & $68,99 \%$ \\
\hline Ago & 300 & 420 & 4620 & 289 & 285 & 245 & 0,9350649351 & 0,8484848485 & 0.8596491226 & $68,20 \%$ \\
\hline Set & 480 & 120 & 5168 & 323 & 318 & 272 & 0,9059767442 & 0,8434109527 & 0.8553459119 & $65,43 \%$ \\
\hline Out & 720 & 300 & 4988 & 311 & 305 & 266 & 0,8554216867 & 0,8546184739 & 0.8721311479 & $63,76 \%$ \\
\hline Nor & 720 & g & 4800 & 300 & 291 & 248 & 0,85 & 0,8266666667 & 0,852233677 & $59,86 \%$ \\
\hline $\mathrm{Dez}$ & 240 & 240 & 3602 & 225 & 222 & 183 & 0,9333333333 & 0,8133333333 & 0.8243243243 & $62,58 \%$ \\
\hline
\end{tabular}

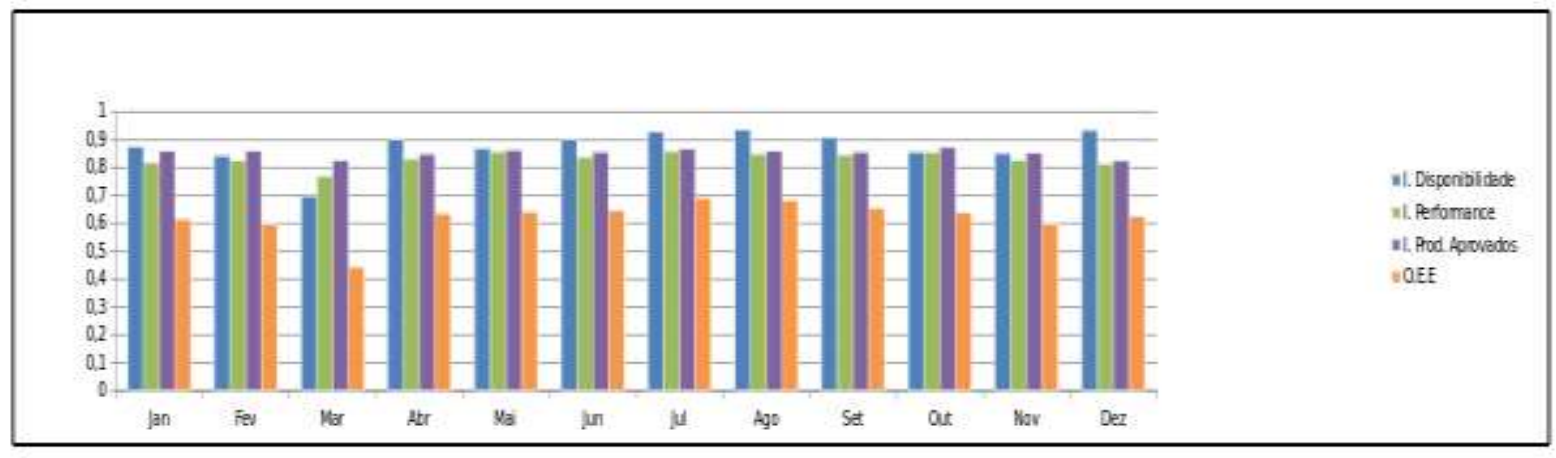

Fonte: Elaborado pelos autores nos laboratórios da Faculdade de Tecnologia Eniac 2014. 
Para elaboração das fórmulas da planilha OEE - Overall Equipment Effectiveness, foi seguido a seguinte linha de raciocínio:

1) Obter o tempo médio produtivo de uma operação padrão (Eficiência).

2) Obter o tempo médio improdutivo dessa mesma operação (Setup para aplicação).

3) Obter o tempo diário disponível para operação (Tempo disponível).

Com esses valores pode-se obter em minutos os valores diários (multiplicado por 60) e mensais (multiplicado pelos dias úteis do mês em questão).

Para a Coluna "P. Não Prog. (min)" foi criada uma aba listando todas as atividades não programadas, por exemplo, quebras, falta de matérias-primas, energia elétrica, ar comprimido, etc. Somando o tempo de cada parada e multiplicando-o por 60, é possível obter em minutos o tempo total de paradas por mês. Assim como na Coluna "P. Não Prog. (min)", foi criada uma Coluna "P. Prog (min)" onde todas as atividades programadas foram listadas, bem como seus tempos para conclusão. Algumas delas são visitas de clientes, manutenções preventivas, limpeza geral, etc. Somando o tempo de cada parada e multiplicando-o por 60, é possível obter em minutos o tempo total de paradas por mês. Multiplicando-se o Tempo Disponível (m/dia) pela quantia de dias úteis no mês e sua resultante subtraída da Coluna "P. Prog (min)" obtém-se os valores da Coluna “Temp Disp. (min)".

Já a Coluna "Disp. de Aplicação (pç)." informa a quantia de peças que podem ser produzidas por mês Essa se obtêm dividindo o resultado da Coluna “Temp Disp (min)" pela soma do tempo total para se realizar uma atividade, ou seja, a soma da "Eficiência (m)" com a "Setup p/ aplic. (m)".

A Coluna "Trabalhos (pç)", é alimentada por outra planilha, essa é alimentada pelos operadores do setor que detalham todos os trabalhos. Por sua vez, esses são separados por mês e alimentam a Coluna "Trabalhos (pç)". A mesma planilha que alimenta o item anterior computa os trabalhos recusados pelos clientes, que preenchem automaticamente a Coluna "Reprodutivos (pç)".

A Coluna "I. Disponibilidade" que é um Indicador OEE, tem seus valores alimentados pela subtração das Colunas “Temp. Disp. (min)" e "P. Não Prog. (min)". O resultado deve ser dividido pela Coluna "Temp. Disp. (min)".

Outro Indicador OEE seria a Coluna "I. Performance", essa possui valores obtidos pela divisão entre as Colunas "Reprodutivos (pç)" e "Disp de Aplicação (pç)". 
"I. Prod. Aprovados" é também um Indicador OEE, essa coluna possui valores provenientes da divisão entre as Colunas "Reprodutivos (pç)" e "Trabalhos (pç).

Por fim, o próprio Indicador OEE é encontrado multiplicando o valor de seus Indicadores, I. de Disponibilidade, I. de Performance e I de Prod. Aprovados. Por mais que o processo de desenvolvimento estivesse sendo aproveitado ao máximo, havia a necessidade de um aumento significativo nesse, sendo assim, o processo de um terceiro robô do setor QC (Robô 3) foi acompanhado e notado que seu tempo de uso se assemelhava ao tempo de uso para desenvolvimento do setor $\mathrm{R} \& \mathrm{D}$, porém, esse uso possuía seu pico em turnos pós administrativos, ou seja, atividades que poderiam ser migradas para apenas um robô (Robô 1), que possuía seu pico produtivo no período administrativo. Além de obter um melhor aproveitamento de recursos do Robô 1, o Robô 3 ficou 100\% disponível para o setor R\&D, dobrando a capacidade de desenvolvimentos desse setor conforme indicado no quadro 2. 
Quadro 2 - OEE após melhoria

OEE- Overall Equipment fffectiveness

\begin{tabular}{|c|c|c|c|c|c|c|c|c|c|c|}
\hline \multicolumn{11}{|c|}{ OEE - Overall Equipment Effectiveness } \\
\hline & Setupp/aplic & Tempo Disponível & Eficiènci & & \multicolumn{2}{|c|}{ Médí de A plizoçòs } & & & & \\
\hline $\mathrm{h}$ & & 8 & & & Di & Mès & & & & \\
\hline$m$ & 8 & & 8 & & 30 & 660 & & & & \\
\hline$m / d \dot{d a}$ & 64 & 480 & 64 & & & & & & & \\
\hline mimès & 1408 & 10560 & 1408 & & & & & & & \\
\hline Mès & \begin{tabular}{|l|l|} 
P.Näo Prog, (min) \\
\end{tabular} & P.Prog,(min) & Temp Disp. (min) & Dispde Apligagio (pc) & Tratalhos (p $(\mathrm{p})$ & Reprodutiuos ( $\left.\mathrm{P}_{\mathrm{r}}\right)$ & 1. Disponibilidade & 1. Performanos & 1. Prod, Aprovados & O.E.E \\
\hline Jan & 120 & of & 9600 & 600 & 585 & 548 & 0,9875 & 0,913333333 & 0,936752137 & $\mathrm{~B} 4,49 \%$ \\
\hline Fey & 60 & 240 & 9360 & 585 & 573 & 53 & 0,993589744 & $0,919 \notin 812$ & 0,93917976 & B5,79\% \\
\hline Mar & 0 & 360 & $8 \pi 0$ & 518 & 530 & 493 & 1 & 0,95267006 & 0,930088679 & $\mathrm{BB}, 62 \%$ \\
\hline $\mathrm{Abr}$ & 0 & 300 & 9780 & 611 & 597 & 555 & 1 & 0,90797546 & 0,929648241 & $B 4,4196$ \\
\hline Mai & 120 & 240 & 9360 & 585 & 583 & 547 & 0,987179487 & $0,93504 z 7 \times$ & 0,9380420 & B6,6196 \\
\hline Juח & 180 & 480 & 9600 & 600 & 597 & 557 & 0,9818 & $0,9 \pi 333333$ & 0,93299838 & 84,996 \\
\hline Jul & 120 & 120 & 10440 & E3 & 608 & 570 & 0,988506747 & 0,87356328 & 0,9375 & B0,96\% \\
\hline Ago & 180 & of & 10560 & 660 & 585 & 548 & 0,982954545 & 0,83030303 & 0,936752137 & $76,45 \%$ \\
\hline Set & of & o & 0 & o & 0 & 0 & \#DIV/o! & \#DIV/o! & \#DIV/o! & \#DIufo! \\
\hline Out & of & 0 & 0 & 0 & 0 & 0 & \#DIV/o! & \#DIV/o! & \#DIV/o! & \#DIufo! \\
\hline Nou & of & 0 & 0 & of & of & 0 & \#DIV/o! & \#DIV/o! & \#DIV/o! & \#DIU/O! \\
\hline Dez & 의 & 의 & o & 의 & 의 & $\underline{0}$ & \#DIV/o! & \#DIV/o! & \#DIV/o! & \#DIU/O! \\
\hline 1 & & & & & & & & & & \\
\hline 0,9 & & & & & & & & & & \\
\hline 0.8 & & & & & & & & & & \\
\hline 0,7 & & & & & & & & & & \\
\hline 0,6 & & & & & & & & & - L. Disponit & ibilidade \\
\hline 0.5 & & & & & & & & & = 1. Perform & nance \\
\hline 0,4 & & & & & & & & & = I. Prod. Ap & provados \\
\hline 0,3 & & & & & & & & & $\cong$ O.E.E & \\
\hline 0,2 & & & & & & & & & & \\
\hline 0,1 & & & & & & & & & & \\
\hline & Jan & Mar & Abr & Jun & Jul & Set & Out & Nov & & \\
\hline
\end{tabular}

Fonte: Elaborado pelos autores nos laboratórios da Faculdade de Tecnologia Eniac 2014. 
Além de serem em robôs diferentes, as aplicações em tecnologia Waterborne e Solventborne, são em cabines diferentes, pois as substâncias químicas que fazem parte de um produto Waterborne, são contaminantes para produtos Solventborne, e vice-versa. Com a economia justificada pela não compra de um novo equipamento, bem como, os ganhos relacionados ao aumento de produtividade, foi possível realizar uma adequação no antigo laboratório de aplicações de tintas do R\&D para instalação do Robô 3 onde foi preparado para recebimento de ambas as tecnologias, embora a tecnologia de aplicações Waterborne não seja a que oferece o maior lucro para a empresa, essa é a tecnologia que as empresas automobilísticas estão buscando, pois a redução e/ou eliminação de solventes na composição química de uma tinta, influencia diretamente em redução de custos e impactos ambientais, que por sua vez reduzem os investimentos em tecnologias para minimização dos impactos ambientais causados pelas cabines de aplicação de tinta em indústrias automotivas.

Com a reforma do antigo centro de aplicações do setor $\mathrm{R} \& \mathrm{D}$, as atividades de desenvolvimento de novas tecnologias e aplicações, não mais irão influenciar no setor QC, pois as 4 horas que eram desprendidas para desenvolvimento impactavam em 4 horas a menos em liberações de lotes, haja vista que o setor de QC deve realizar aplicações de amostras de todos os lotes produzidos utilizando os critérios de aplicação concedidos pelo setor
R\&D. Outro fator que contribuiu com o aumento na qualidade dos trabalhos de aplicação, foi que a partir do momento que o setor de R\&D dispunha de um centro de aplicações, esse serviu para treinamento e capacitação de funcionários especializados em aplicações de tintas. Anteriormente as aplicações nos robôs eram feitas pelos técnicos químicos e coloristas que desenvolviam e formulavam as tintas. Como o cento de aplicações do setor $\mathrm{R} \& \mathrm{D}$ possui técnicos especializados em aplicação, os técnicos em química e coloristas não necessitam desenvolver materiais para desprender seu tempo com aplicação, suas amostras são encaminhadas ao centro de aplicações, onde será avaliada e aplicada de acordo com as reais necessidades, respeitando todas as variáveis de aplicação como; temperatura da cabine, temperatura da tinta, umidade da cabine, distância de aplicação, aplicador, sino atomizador e bico (seguindo todas as normas estabelecidas entre as montadoras e a empresa).

\section{Considerações Finais}

Embora uma sólida e funcional estrutura de desenvolvimento de novos produtos já faça parte da empresa, mesmo ela possuindo histórico de sucesso em variados aspectos de produtividade, segurança e mercado, deve-se sempre utilizar seus conhecimentos, juntamente com embasamento teórico, para demonstrar aos 
responsáveis e/ou clientes que uma mudança setorial e até cultural pode melhorar o fluxo de trabalho de uma empresa, aumentar a lucratividade e melhorar o uso de recursos. Um dos aspectos fundamentais para que o objetivo de um projeto seja cumprido é o conhecimento. Todas as etapas de desenvolvimento de um projeto serão questionadas, pois possível alteração em uma estrutura, muitas vezes funcional e cômoda, envolve investimentos financeiros ou até situações irreversíveis ao processo.

Através da ferramenta OEE (Overall Equipment Effectiveness) foi possível demonstrar o melhor uso de um equipamento ao setor de desenvolvimento $R \& D$, esse por sua vez aumentou em média $98 \%$ entre desenvolvimento de novos produtos e soluções personalizada aos processos de clientes, havendo melhor uso de equipamento e pessoal, além da disponibilidade exclusiva dos equipamentos de liberação de lote ao setor de QC. O ganho na versatilidade do robô, analisado juntamente ao fabricante desse, foi dada pelo conhecimento da aplicação do produto final em diversos aspectos, como comportamento físico e químico associados a cargas de alta tensão. Embora robôs de aplicação sejam desenvolvidos para uma tecnologia, foi desenvolvida uma solução para que um robô de pintura aplique qualquer tecnologia em tintas e vernizes, tornando-o um equipamento que já estava em uso e já possuía um cycle time definido para atendimento de produtos desenvolvidos para apenas dois clientes, em um equipamento versátil para todos os clientes, que aumentou a produtividade, qualidade e com garantia mantida por seu fabricante.

\section{Referências}

BARIANI, L. Utilização da Tecnologia da Informação por Grupos Integrados de Manufatura para o Controle de Indicadores de Produção Enxuta - Um Estudo de Caso. Dissertação de Mestrado - Universidade de Taubaté. 2006.

BONACORSO, Nelson Gauze; Noll, Valdir. Automação Eletropneumática. 11.ed. São Paulo: Érica. 2009.

COLESTOCK, Harry. Industrial Robotics: Kentucky: McGraw-Hill. 2010.

CRUZ, Eduardo Cesar Alves; Choueri Jr., Salomão. Automação Eletrônica Aplicada. 2.ed. São Paulo: Érica. 2013.

GEORGINI, Marcelo. Automação Aplicada. 9. ed. São Paulo: Érica. 2013.

GROOVER, Mikell P. Automação Industrial e Sistemas de Manutenção. 3.ed. São Paulo: Pearson. 2011.

KARDEC, Alan; NASCIF, Júlio. Manutenção: Função Estratégica. 2002, Qualitymark. 
MORAES, Cicero Couto; Castrucci, Plínio de Lauro. Engenharia de Automação industrial. 2.ed. São Paulo: LTC. 2007.

NAKAJIMA, S. Introdução ao TPM - Total Productive Maintenance. São Paulo: IMC Internacional Sistemas Educativos Ltda., 1989.

OEE Industry Standard. Disponível em $<$ http://www.oeeindustrystandard.org $>$. Acesso em: 10 de setembro de 2014.

ROSÁRIO, João Mauricio. Princípios de Mecatrônica. São Paulo: Pearson. 2005.

SANTOS A. C. \& SANTOS, M. J. Utilização do Indicador de Eficácia Global de Equipamentos (OEE) na gestão de melhoria contínua no sistema de manufatura - Um Estudo de Caso: Encontro Nacional de Engenharia de Produção (ENEGEP) - São Carlos. 2010. 